\title{
The presence of the patients' family after the surgery and its role in the postoperatore delirium incidence
}

\begin{abstract}
Background: Postoperative delirium is a common and deleterious complication in geriatric patients, and always has been associated with extent of day stay in hospital, and certainly more cost for the hospital as well. The delirium causes an increased mortality and an increasing of mental status deterioration characterized by reduction of environmental recognition as well as the disorder of alertness. The purpose of this study is to highlight the role of the presence of the patients' family in preventing postoperatore delirium in elderly patients in urology.
\end{abstract}

Material and method: This study is a prospective random double blinded study. Participants of this study are 456 patients older than 65 years old, while they were admitted to the urology department, between January 2010 December 2012. All patients are evaluated preoperatively on MMSE. The comparing value that was used for delirium was CAM. Patients that had been diagnosed and treated for psychiatric problems (Alzheimers, Dementia senile, Scysophrenia) were excluded from the study.

Results: There was no difference between patients concerning the surgery type, anaesthesia, preoperatore comorbidity, hemodynamic changes. The difference between the two groups of patients was whether they met their family or not the two first days after the surgery. It is noticed that all patients who had contacts with their family after the surgery $306(100 \%)$ experienced no delirium, while 50 of the patients who did not have contacts with their family experienced delirium $(33.3 \%) \mathrm{p}<0.01$.

Conclusion: Having contact with their family the two first days after the surgery decreases significantly the incidence of postoperatore delirium in elderly patients in urology $\mathrm{p}<0.01$.
Volume 10 Issue 2 - 2018

\author{
Haxhire Gani,' Majlinda Naço,' Aurel Janko,' \\ Bilbil Hoxha,' Herion Dredha,' Franceska \\ Beqiri, ${ }^{2}$ Vjollca Shpata' \\ 'Anesthesi-Intensive Care,Albania \\ ${ }^{2}$ Studente Royal College of Surgeon in Ireland Medical \\ University of Bahrain, Bahrain
}

Correspondence: Haxhire Gani,Anesthesi-intensive care,

Tirana,Albania, Email haxhireganii@yahoo.com

Received: February 14, 2018 | Published: March 14, 2018

\section{Introduction}

Postoperative delirium (POD) is a frequent postoperative disorder to the sick and elderly, and always has been associated with extended of day stay in hospital, and certainly more cost for the hospital as well. ${ }^{1}$ Causes of postoperative psychotic disorders (POPD) are multi-factorial. Mechanisms that contribute to PODP are not well known. A lot of theories support abnormal neurotransmission during this period. One widely accepted mechanism is cholinergic deficit. ${ }^{2}$

The Postoperative delirium on elderly patients causes an increased mortality and an increasing of mental status deterioration characterized by reduction of environmental recognition as well as the disorder of alertness. Increasing numbers of elderly patients are undergoing an increasing variety of surgical procedures. ${ }^{4}$ With the increase of the life span of the patients, the urologic surgeries in these group of elderly patients are also increased. The surgery plays an important role on emotional and spiritual deterioration on elderly patients. The prevalence of postoperative delirium in elderly patients ranges from $0 \%$ to $73 \%$, depending on the study and type of surgery. 3,5 The prevalence of postoperative delirium in elderly patients ranges from $0 \%$ to $73 \%$, depending on the study and type of surgery .The increased average population age in Albania, and in the entire world, leads to increased number of patients that are elderly and that undergo surgery. Elderly population has a higher risk of delirium on post postoperative, compared with the other population. The purpose of this study is to highlight the role of the presence of the patients' family in preventing postoperatore delirium in elderly patients in urology.

\section{Material and method}

This study is a prospective random double blinded study. Participants of this study are 456 patients older than 65 years old, while they were admitted to the urology department. All patients are evaluated preoperatively on MMSE. The comparing value that was used for delirium was CAM. Patients that had been diagnosed and treated for psychiatric problems (Alzheimers, Dementia senile, Scysophrenia) were excluded from the study. The effectiveness of routine screening of postoperative Delirium in the elderly using Confusion Assessment Method (CAM). Psychiatrists are not necessary in this case. This study is prospective and random. This study is accomplished by Anesthesiology and Reanimation Service of the Urology Clinic of the University Hospital Center ' Mother Theresa', Tirana, Albania. Some Anesthesiologists have completed preoperative and intraoperative data but did have no idea of the Study. These data are opened only at the end of the study by team in charge of the study composed by other Anesthesiologists and Reanimators. The Team in Charge of the study has collected other data too about the incidence of acute postoperative complications in elderly patients. Cognition is made with evaluation of MMSE, 24 hour preoperative data from one Anesthesiologist not included in the Team in charge of study. Patients with less than 23 points, are not included in this study ${ }^{6}$ Diagnosis is confirmed with the 'gold standard' test, Confusion Assessment Method (CAM), which is administered without any laboratory examinations or radiological tests, in patients who do not have any apparent physical disorder. ${ }^{7,8}$ There was no difference between patients concerning the surgery type, anaesthesia, preoperatore comorbidity, hemodynamic changes. The difference between the two groups of patients was whether they met their family or not the two first days after the surgery. $p$ value $\leq 0.05$ was considered statistically significant (Tables $1-3$ ). 
It is noticed that all patients who had contacts with their family after the surgery $306(100 \%)$ experienced no delirium, while 50 of the patients who did not have contacts with their family experienced delirium (33.3\%) had been significantly statistically difference between of them $(\mathrm{RR}=8.1,95 \% \mathrm{CI}=5.6$ $11.8, \mathrm{p}<0.01)$

Table I Data of age

\begin{tabular}{llll}
\hline $\begin{array}{l}\text { Age } \\
\text { (years) }\end{array}$ & $\begin{array}{l}\text { No. of } \\
\text { patients }\end{array}$ & $\begin{array}{l}\text { Gender } \\
\text { F }\end{array}$ & M \\
\hline $65-70$ & 112 & 12 & 100 \\
$71-75$ & 148 & 9 & 139 \\
$76-80$ & 124 & 7 & 117 \\
$>81$ & 72 & 2 & 70 \\
Total & 456 & 30 & 426 \\
\hline
\end{tabular}

Table 2 General data

\begin{tabular}{|c|c|c|c|}
\hline & $\begin{array}{l}\text { Patient } \\
\text { with } \\
\text { delirium }\end{array}$ & $\begin{array}{l}\text { Patient } \\
\text { without } \\
\text { delirium }\end{array}$ & Value of $p$ \\
\hline Duratio of surgery/min & $62 \pm 21$ & $65 \pm 27$ & $\mathrm{p}=0.6(\mathrm{NS})$ \\
\hline Open surgery/Endoscopy & $6 / 44$ & $51 / 355$ & $\mathrm{p}=0.7(\mathrm{NS})$ \\
\hline Loss of blood/ml & $340 \pm 120$ & $350 \pm 120$ & $\mathrm{p}=0.8(\mathrm{NS})$ \\
\hline Age of patientd/years & $79 \pm 7$ & $78 \pm 7$ & $\mathrm{p}=0.6(\mathrm{NS})$ \\
\hline $\begin{array}{l}\text { Preoperatory } \\
\text { comorbodity }\end{array}$ & II & 83 & $\mathrm{p}=0.6(\mathrm{NS})$ \\
\hline $\begin{array}{l}\text { Endotracheal anaesthesia/ } \\
\text { Spinal anaesthesia }\end{array}$ & $4 / 46$ & $42 / 364$ & $\mathrm{p}=0.8(\mathrm{NS})$ \\
\hline
\end{tabular}

* NS, no statistically significant

Table 3 The role of delirium incidence when there was no contact with their family the first two days after the surgery

\begin{tabular}{lllll}
\hline & & Delirium & No delirium & Total \\
\hline & Yes & 0 & 306 & 306 \\
$\begin{array}{l}\text { Contact } \\
\text { with their } \\
\text { family }\end{array}$ & No & 50 & 100 & 150 \\
& Total & 50 & 406 & 456 \\
\hline
\end{tabular}

\section{Discussion}

Early postoperative delirium is a problem not only for the welfare of the patients during surgery, but also for the prolongation of the patients' day stay in hospital, and is also a predisposing factor that these patients have postoperative delirium, even after being discharged from the hospital. Cognitive postoperative deterioration, is a general and important problem in elderly patients, after cardiac and non cardiac surgery. ${ }^{6,9}$ The results of this study show that communication between patients and their family members decreases significantly incidence of postoperative delirium where, of course other predisposes factors like massive loss of blood, need for hemotransfusion, hemodynamic instability, hypoglycemia and hyperglycemia etc are not present. Knowing that postoperative delirium is usually accompanied with post operatory complications it is very important that we acknowledge the value of the presence of family members in preventing this complication without medication a cost. Results showed that appropriate relationship of the family with the patient, through structured and regular visits to the patients after cardiac surgery, notably reduced the incidence of delirium in the patients in the study group ${ }^{10}$ Brunton et al. in a study on family participation in the prevention of delirium in the elderly, hospitalized in ICU, showed that family members could be used to prevent delirium. ${ }^{10}$

Based on the results, family members can be used to make the feeling of health and ability in their patient to cope with this condition. ${ }^{11,12}$ In fact their results support the role of family participation in the prevention of delirium and are consistent with the present study. ${ }^{13}$ Family members should be counted as a treatment team through formation of a positive environment and its direct effect on disease outcomes. ${ }^{14}$

\section{Conclusion}

Having contact with their family the two first days after the surgery decreases significantly the incidence of postoperatore delirium in elderly patients in urology $\mathrm{p}<0.01$

\section{References}

1. Gani H, Domi R, Kodra N, et al. The incidence of postoperative delirium in elderly patients after urologic surgery. Med Arch. 2013;67(1):45-7.

2. Haxhire Gani, Pirro Prifti, Majlinda Naco, et al. The incidence of postoperative delirium in elderly patients undergoing urologic surgery Anaesthesia, Pain and Intensive Care.

3. Haxhire Gani, Pirro Prifti, Rudin Domi, et al. The Importance of Postoperative Delirium (POD) on Elderly Patients in Urology in Increasing the Day Stay in Hospital. British Journal of Medicine and Medical Research. 2016;18(1):1-10.

4. Guidelines Peri-operative care of the elderly 2014 Association of Anaesthetists of Great Britain and Ireland Membership of the working party

5. Dyer CB, Ashton CM, Teasdale TA. Postoperative delirium. A review of 80 primary data-collection studies. Arch Intern Med. $1995 ; 155(5): 461-465$.

6. Inouye SK. The Confusion Assessment Method (CAM): Training Manual and Coding Guide. 2003; Yale University School of Medicine.

7. Marcantonio ER, Flacker JM, Michaels M, et al. Delirium is independently associated with poor functional recovery after hip fracture. J Am Geriatr Soc. 2000;48(6):618-24.

8. Fong HK, Sands LP, Leung JM. The role of postoperative analgesia in delirium and cognitive decline in elderly patients: a systematic review. Anaesth Analg. 2006;102(4):1255-1266.

9. Gani H, Naco M. Very important anaesthesis role on studing (elderly) cognive complication postoperatively. Journal of Medica Sciences. 2010;42(1):90-92.

10. Maryam Eghbali B, Nasrin S, Tayebe M. Effect of Family-Patient Communication on the Incidence of Delirium in Hospitalized Patients in Cardiovascular Surgery ICU. Iran J Nurs Midwifery Res. 2017;22(4):327-331.

11. Gay EB, Pronovost PJ, Bassett RD, et al. The intensive care unit family meeting: making it happen. J Crit Care. 2009; 24(4):629.e112 .

12. Curtis JR, Ciechanowski PS, Downey L, et al. A Development and evaluation of an interprofessional communication intervention to improve family outcomes in the ICU. Contemp Clin Trials. 2012; 33(6): $1245-54$ 
13. Brunton D, Henneman E, Inouye SH. Feasibility of family participation in a delirium prevention program for hospitalized older adults. J Gerontol Nurs. 2010;36(9):22-33.
14. Zolfaghari M, Arbabi M, Pedram Razi S, et al. Effectiveness of a Multifactor Educational Intervention on Delirium Incidence and Length of Stay in Patients with Cardiac Surgery. Hayat. 2012;18:6778 . 